\begin{tabular}{|c|c|}
\hline 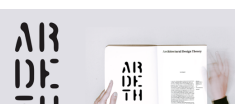 & $\begin{array}{l}\text { Ardeth } \\
\text { A magazine on the power of the project }\end{array}$ \\
\hline & $\begin{array}{l}71 \\
\text { Eu }\end{array}$ \\
\hline
\end{tabular}

\title{
RE: Theorizing Vulnerability
}

\section{Bryony Roberts}

\section{(2) OpenEdition \\ Journals}

Electronic version

URL: https://journals.openedition.org/ardeth/2028

ISSN: 2611-934X

Publisher

Rosenberg \& Sellier

Printed version

Date of publication: 1 December 2020

Number of pages: 197-201

ISSN: 2532-6457

Electronic reference

Bryony Roberts, "RE: Theorizing Vulnerability", Ardeth [Online], 7 | 2020, Online since 01 June 2021, connection on 25 June 2021. URL: http://journals.openedition.org/ardeth/2028

CC BY-NC-ND 4.0 


\title{
RE: \\ Theorizing Vulnerability
}

\section{Commentary}

Bryony Roberts

\begin{abstract}
This commentary considers the relevance of theory in the context of the COVID-19 pandemic and protests against racial injustice. The events of 2020 have called attention to the visceral, lived conditions of illness, poverty, and injustice and the systemic conditions that perpetuate them. As the limitations of existing institutions and bodies of knowledge are exposed, it becomes urgent to cultivate alternative ways of knowing and practicing. This commentary builds on the recently edited volume Log 48: "Expanding Modes of Practice" to discuss how theories and practices of intersectional feminism can bridge the scales of personal, visceral experience and systemic analysis to think outside of existing frameworks and imagine change.
\end{abstract}

Affiliatio

Columbia University, Graduate School

of Architecture,

Planning and Preservation

Contacts:

bwr2102 [at]

columbia [dot] edu

DOI:

10.17454/ARDETH07.13

ARDETH \#07 
The COVID-19 pandemic has made palpable for even the most fortunate the vulnerabilities of physical, financial, and psychological uncertainty. For those less fortunate, the everyday struggle to meet basic needs is reaching frantic desperation. In the United States, recurring instances of racial violence are compounding experiences of disparity and igniting protests around the country. What, then, could be the relevance of theory in the face of bald physical suffering and heightened social inequity? A cerebral domain of word-play and intertextual references, the medium of theory itself is aligned with logos rather than the tangible realm of physical need, suffering, and relief.

Certainly, theory cannot solve a global health or economic crisis. It can, potentially, lay the groundwork for the societies and economies that are rebuilt in the wake of these crises. Theories capable of addressing tangible experiences of poverty, illness, and oppression - that illuminate conditions of everyday lived reality and their connections to systemic inequities - are essential to thinking alternative futures. Fortunately, there are many lineages of critical thought that have challenged mind/ body dualities in western thought and have developed languages - often slippery and personal - of addressing the relation between corporeal experience and systemic conditions. This lineage offers a door to theory capable of addressing the depth of suffering now, and capable of stitching theory back into the world.

Throughout 2019 and early 2020, at the invitation of editor Cynthia Davidson, I developed a guest-edited issue of the architectural journal $L o g$ titled "Expanding Modes of Practice," which was published at the end of March 2020, just as the pandemic was accelerating globally. At its core, this issue is exploring the implications of intersectional feminism for architectural practice - asking how attention to the overlapping inequities of gender, race, class, and sexuality opens up alternative modes of thinking, working, and being. A common theme throughout the contributions by historians, theories, and practitioners, addressing both historical case studies and contemporary practices, is the simultaneous consideration of both the concrete specifics of everyday experiences and the large-scale political, social, and economic systems. This mixing of the personal and the systemic, the specific and the abstract, the messy and the categorical intentionally breaks down hierarchies embedded in established theories and historiographies, making room for individual experiences overlooked by institutionalized canons. While intended to confront how architecture can address social complexities, the issue themes became tragically more relevant to the crisis of the pandemic. If there was ever a time when architectural theory and practice needed to find ways of addressing personal, physical, and embodied needs, it is now.

Women, communities of color, and populations in the global south are hit hardest by COVID-19 through the compounded burdens of care 
work, precarious working conditions, and underfunded health systems. Addressing their experiences requires expanding ways of knowing. There are parallel lineages of theory that have explored how attention to specific, embodied experience can offer resistance to established patriarchal, capitalist, and colonial systems. Phenomenology has long been the dominant discourse on experience, producing a range of positions over time that alternatively destabilize and reify the concept of a universal subject. In contrast, theoretical work in feminist, queer, and critical race theory (sometimes reworking phenomenological methods) has offered frameworks for analyzing the specific, embodied experiences of individuals and producing modes of situated solidarity and resistance. As Judith Butler articulated in Gender Trouble, the mind/body duality that has been pervasive in western philosophical discourse, beginning with Plato and continuing through Descartes, Husserl, and Sartre, supports a hierarchy of reason over corporeality and maintains the fantasy of escaping physicality into a transcendent realm of abstraction. This duality is not merely a philosophical trope, but has profound implications for conceptions of gender. She states, "the cultural associations of mind with masculinity and body with femininity are well documented within the field of philosophy and feminism. As a result, any uncritical reproduction of the mind/body distinction ought to be rethought for the implicit gender hierarchy that the distinction has conventionally produced, maintained, and rationalized" (Butler, 1999: 17). This mind/body distinction has been central to not only justifications of unequal gender roles but also large-scale projects of colonialism. As Maria Lugones describes, “coloniality" depends on conceptualizing colonizers as rational beings and indigenous populations as primitive, sexualized beings, thereby justifying the dehumanizing actions of slaughter, rape, and the destruction of cultures, as well as ongoing contemporary exploitation through the disparities between the global north and global south. But there are nonetheless important moments of friction when the "logic and efficacy [of coloniality] are met by different concrete people whose bodies, selves in relation, and relations to the spirit world do not follow the logic of capital" (Lugones, 2010: 754). The collision of conceptual systems with specific bodies enacts both the moment of oppression but also the opening for resistance. The inexact and individual realization of a system offers a moment of interpretation and possible subversion. Attention to the physical realm is therefore not only informative for mounting critiques of existing philosophical systems but also for finding modes of expression and liberation that emerge from physical and material practices.

While feminist, queer, and critical race theories and their activist counterparts are significantly distinct, and by no means collapsible into easy unity, the last few years have seen notable moments of solidarity both in theory and in activism. More than 30 years since Kimberlé Crenshaw first coined the word 'intersectional' in 1989 (Crenshaw, 1989: 140), 
the idea of intersectionality - of seeing the overlapping oppressions of gender, race, class, sexuality, and ableness as inextricable - is mobilizing both thought and action, perhaps in response to the rise of populist extremism and inflammatory leadership across multiple nations. Common themes are emerging: the tendency to probe both the macro systems and micro social interactions that produce interlocking oppressions and to articulate both individual subjective experiences and structural critiques. If theory since the early 20th century has wrestled with the question of how to proceed when there are no objective universal truths, this multi-scalar elision of the personal and the systemic opens up alternative answers to these recurring questions.

What are the implications of these theoretical and activist projects for architecture and urbanism? As discussed in the earlier issue of Ardeth \#05, edited by Andres Jaque, innovation is no longer seen as a neutral endeavor, but rather one entangled in specific social, political, economic, and ecological contexts. The writings of Bruno Latour and Donna Haraway, both referenced frequently in the issue, offer theoretical foundations for imagining invention as a compromised but still valuable endeavor-one achieved by wading knee-deep through one's one contextual limitations, reaching for commonalities and solidarities with others who are themselves mired in their own biases. The assumption that we are all compromised, all limited, all entangled is an invaluable starting point for alternative epistemologies and practices. Brutal honesty and self-reflection create the possibilities for profound coalitions. As Haraway describes, "we do need an earth-wide network of connections, including the ability partially to translate knowledge among very different-and power-differentiated-communities” (Haraway, 1988: 580).

"Expanding Modes of Practice” gathers practitioners, theorists, and historians who are finding ways of practicing from their own entanglement. Bringing their own narratives, cultural contexts, and relationships, they approach all of their collaborators as complex embodied individuals with their own cultural histories. They integrate community engagement methods from urban planning, heritage studies, and social practice into processes of research and design to address the complexity of social conditions - using interviews, workshops, oral histories, and collaborations. Writing humorously personal critiques of patriarchy, organizing intergenerational workshops to gather oral histories, leading collaborative design processes using piles of 99-cent store objects, working with individual small business owners to navigate regulatory legislation, contributors such as Deborah Garcia, Paola Aguirre, LA Mas, Hector, Mabel O. Wilson, and Ana Miljacki show that both theory and practice can be deeply personal and also work towards large-scale systemic change. 
This moment calls for a capacity to bridge between abstraction and specificity, to create bodies of knowledge that emerge from the brutal realities of bodies in social and economic disparity. A future that builds from this present has to start with unabashed, honest looking.

\section{References}

Butler, J. (1999 [1990]), Chapter 1: Subjects of Sex/Gender/Desire, in Gender Trouble: Feminism and the Subversion of Identity, New York, Routledge.

Lugones, M. (2010), Toward a Decolonial Feminism, "Hypatia”, vol. 25, n. 4.

Crenshaw, K. (1989), Demarginalizing the Intersection of Race and Sex: A Black Feminist Critique of Antidiscrimination Doctrine, Feminist Theory and Antiracist Politics, Chicago, University of Chicago Legal Forum, vol. 3, n. 1.

Haraway, D. (1988), Situated Knowledges: The Science Question in Feminism and the Privilege of Partial Perspective, "Feminist Studies", vol. 14, n. 3. 